\title{
Inequities in healthcare
}

\author{
José G Merino US research editor
}

The BMJ

Migrants can face many hardships in their search for a new life. On the journey, unofficial migrants may risk their lives crossing perilous terrains and dangerous waters. After the trip, they are at risk for illness and might not receive adequate medical treatment; since September, at least six migrant children have died after getting ill in the holding areas of US Border Patrol. ${ }^{1}$ After they settle in their new country, they still face barriers when accessing healthcare. ${ }^{2}$

As detailed in this Feature (doi:10.1136/bmj.12281), NHS hospitals in England are obliged to check eligibility for free NHS care and to charge non-eligible migrants $150 \%$ of the national tariff. As a result, some migrants do not seek care for fear of getting turned away, of running up debts they cannot pay, or of being identified for deportation. For this reason, some medical royal colleges and others have called for suspension of the government's charging policy. One of the goals of the policy is to curb health tourism, but this care costs the NHS only $0.3 \%$ of its budget, and the cross border movement of doctors and patients has a positive effect on the countries sending and receiving them (doi:10.1136/bmj.12208). Despite these benefits, discrimination and health disparities related to race and ethnicity can harm patients and lead to inequalities in opportunities and rewards for ethnic minority doctors (doi:10.1136/bmj.12226).
Women in medicine also face discrimination, as well as lack of opportunities, challenges obtaining senior positions, and lower pay. ${ }^{3}$ This year, $94 \%$ of English NHS organisations reported a gender pay gap that favours men-and the trend has worsened since last year (doi:10.1136/bmj.12089). The pay gap among doctors far exceeds that in the NHS in general: male doctors earn on average $17 \%$ more than female doctors, perhaps because there are fewer women in the higher echelons of the profession. Systemic features in medicine and the NHS, such as difficulties for part time working and a culture of bullying, as well as unconscious biases hamper the advancement of women in medicine, to the detriment of all of us. But there are hopeful signs-including the fact that the Royal College of Physicians is looking into ways to tackle the discrepancies-that the culture may be changing (doi:10.1136/bmj.12312). We must work to make sure that this happens.

1 Hennessy-Fiske M. Six migrant children have died in US custody. Here is what we know about them. Los Angeles Times 2019 May 24. https://www.latimes.com/nation/la-namigrant-child-border-deaths-20190524-story.html

2 Hoffman J. Sick and afraid, some immigrants forgo medical care. New York Times 2017 June 26. https://www.nytimes.com/2017/06/26/health/undocumented-immigrants-healthcare.html

3 Frellick M. Gender paygap exists for doctors, especially in Maryland. 2018 Aug 2. https: //www.medscape.com/viewarticle/900128

Published by the BMJ Publishing Group Limited. For permission to use (where not already granted under a licence) please go to http://group.bmj.com/group/rights-licensing/ permissions 